\title{
Permanent Deformation Characteristics of Coarse Grained Subgrade Soils under Train-Induced Repeated Load
}

\author{
Xianzhang Ling, ${ }^{1}$ Peng Li, ${ }^{1}$ Feng Zhang, ${ }^{2}$ Yingying Zhao, ${ }^{1}$ Yan Li, ${ }^{1}$ and Lingshi An ${ }^{1}$ \\ ${ }^{1}$ School of Civil Engineering, Harbin Institute of Technology, Heilongjiang, Harbin 150090, China \\ ${ }^{2}$ School of Transportation Science and Engineering, Harbin Institute of Technology, Heilongjiang, Harbin 150090, China \\ Correspondence should be addressed to Peng Li; hit_lp@163.com
}

Received 30 August 2016; Revised 12 December 2016; Accepted 26 December 2016; Published 6 February 2017

Academic Editor: Donato Sorgente

Copyright (c) 2017 Xianzhang Ling et al. This is an open access article distributed under the Creative Commons Attribution License, which permits unrestricted use, distribution, and reproduction in any medium, provided the original work is properly cited.

\begin{abstract}
This paper presents the results of a laboratory experiment that aimed to characterize the permanent deformation behavior of coarse grained soils. To evaluate the effects of the cyclic stress amplitude, initial mean stress, and initial stress ratio on the permanent axial deformation, six series of repeated load triaxial tests were performed. The results indicate that permanent deformation of coarse grained soils increased with increasing cyclic stress amplitude. In particular, for relative low cyclic stress levels, accumulation rate of permanent deformation decreased progressively with number of cycles and eventually reached an equilibrium state. The initial stress ratio was also found to obviously facilitate the buildup of axial deformation since it means higher deviatoric stress as the mean pressure kept constant. As the initial stress ratio was less than the slope of static failure line, the experimental results indicated that the increase of initial mean stress enhanced the capability of resisting deformation. A simplified mechanistic empirical prediction model was proposed, which predicted the permanent deformation as product of four independent functions about cyclic stress amplitude, initial mean stress, initial stress ratio, and number of load cycles. Satisfactory predictions of the permanent deformation behavior of coarse grained soils were obtained with the proposed model.
\end{abstract}

\section{Introduction}

Increased wheel loads and speeds of freight rail traffic are accelerating the track deterioration of railway lines. In general, a dominant factor of the deterioration in ballasted tracks is uneven subsidence of ballast and subgrade layer due to the cumulative plastic deformation. So as the foundation of track structure, a properly compacted good quality subgrade will effectively absorb and dissipate train vibration loads and further provide strong underneath supports to the upper components through high shearing resistance. In real project, the guidelines for deformation control during track subgrade construction are generally based on the method of setting a reserved settlement amount. Thus, detailed understanding and characterization of the deformation behavior of subgrade soils are a prerequisite for both the construction and subsequent maintenance of railway substructure.

Coarse grained soils, which are generally the main construction materials of subgrade layer in railway system, usually present two types of deformation behavior when subjected to repeated traffic-type dynamic load: (a) resilient or recoverable deformation, which is related to the loadcarrying ability of track structure, reflects stiffness properties of the material and (b) residual or irreversible deformation, which contributes to most of the subgrade settlement, determines long-term performance of railway line [1-4]. Although small compared to the resilient deformation, the residual deformation accumulates in each load cycle and may eventually reach a significantly large value that causes subgrade failure.

Over the years, considerable investigations have been devoted to characterizing the resilient behavior of soils using laboratory techniques, and lots of mathematical models have been developed to predict resilient response considering the effects of stress levels, void ratio, and some other factors [5-8]. For instance, in view of the material nonlinearity, Seed [9] introduced the concept of resilient modulus first, which was defined as the ratio of cyclic stress level to recoverable axial strain, and some similar definitions were widely used by later researchers. In contrast, the permanent 
deformation behavior of coarse grained soils is still less clearly known in practice. Although it is easy to measure the settlement in railway subgrade, exact prediction of the permanent deformation development is an extremely difficult matter. The most possible reason is that the deformation accumulation under repeated loading is a time-consuming process affected by too many factors, and the obtained test results are much more scattered than resilient modulus tests $[10,11]$.

The permanent deformation investigations are mostly based on repeated load triaxial tests, and stress state unquestionably is the most important factor affecting the development of permanent deformation for coarse grained soils. In early stage, some investigations based on repeated load triaxial tests found that, to a certain physical condition, the permanent axial strain clearly increased with increasing cyclic stress and decreasing confining pressure [12]. In this sense, it is principally some forms of stress ratio $\sigma_{d} / \sigma_{3}$ that governed the permanent deformation behavior in the tests, and more research attention was paid to the deformation prediction model based on that stress ratio. Afterwards, several research workers also attempted to correlate the results under repeated loading with the failure deviator stress from monotonic tests [13-15]. In such an approach, the failure line was considered as the boundary of equilibrium state and incremental collapse, and the amount of permanent deformation could be determined by how close the applied stress path to the material failure line. Raymond and Williams [16] introduced a stress ratio of the maximum deviator stress divided by monotonic failure stress to characterize the test results and reported good correlation with laboratory observations. It is important to note that the anisotropic consolidation cases are not considered in this method; that is to say, the same permanent strain will be obtained as long as identical maximum deviator stresses are applied. Pappin [17] observed this problem and alternatively described the permanent strain with ratio of deviator stress amplitude to mean normal stress. Good performances of this model were reported without other verification found in the literatures. However, several researchers [18] have investigated and questioned the approach of predicting the permanent deformation of coarse grained soils under repeated loading based on monotonic failure stress, since unreasonable results were obtained for describing their experimental data. They argued that the failure of specimen under monotonic loading presented as sudden collapse, but it was a gradual process when subjected to cyclic loading, so the structural response of the materials may not be the same in these two kinds of tests.

Generally, most of the experimental results show that permanent deformation buildup of coarse grained soils under repeated loading is actually a ceaseless gradual process, which means that in each load repetition a small strain increment will be accumulated to the total deformation. Morgan [19] conducted a series of repeated load triaxial tests with up to $2 \times 10^{6}$ load cycles and found that the increase of permanent strain did not cease even at the end of the tests. Based on this deformation behavior, lots of prediction models without asymptotic values were proposed $[20,21]$. In the meantime, still some researchers believed that the deformation at relative low stress levels will eventually reach an equilibrium state, during which no further permanent strain increase occurred with increasing number of load cycles [18, 22-24]. So it can be seen that, maybe due to the material nonlinearity caused by large particles, the permanent deformation behavior of coarse grained soils varies significantly under the same loading conditions.

The major objective of this research is to examine the influence rules of the factors such as cyclic stress amplitude, initial mean stress, and stress ratio and to develop an improved empirical model for capturing the permanent deformation behavior of coarse grained soils under traininduced repeated loading. The model is developed based on repeated load triaxial tests where it is possible to analyze the deformation behavior for a wide range of stress conditions, especially for the isotropic consolidation cases common in subgrade layer. Some widely used existing prediction models will also be compared with the present model to verify its performance.

\section{Existing Permanent Deformation Models}

Permanent deformation prediction models are generally divided into two categories: incremental models based on elastoplastic theory and mechanistic-empirical models from plentiful test data [26]. Incremental models can accurately quantify the effects of stress amplitudes and paths on the permanent deformation, but the complex and time-consuming nature also makes them hard to implement. In contrast, mechanistic-empirical models can generally produce prediction results in acceptable accuracy with less parameter and computing time, so they are more widely used in practical subgrade design. Although plenty of empirical models have been proposed by different researchers, only some famous and widely used ones are summarized in this section.

The first well-known prediction model is that proposed by Barksdale [20], who performed repeated load triaxial tests on various base coarse materials, and proposed a linear relationship between permanent axial strain and the logarithm of number of load cycles as

$$
\varepsilon_{\mathrm{acc}}=a+b \log N
$$

Later, Monismith et al. [27] and Sweere [21] found that the semi-log model did not well fit the experimental data for larger numbers of load cycles, so a power law model or log-log model was suggested as follows:

$$
\begin{aligned}
\varepsilon_{\mathrm{acc}} & =a N^{b} . \\
\log \varepsilon_{\mathrm{acc}} & =a+b \log N
\end{aligned}
$$

Wolff and Visser [28] performed a series of full-scale heavy vehicle simulator tests on granular materials with millions of load cycles but observed that both the logarithm model and log-log model tended to underestimate the permanent strain at small number of load cycles and in reverse overestimate it for larger cycles. Based on test results, they 
described the buildup of permanent strain with a model consisting of two phases like

$$
\varepsilon_{\mathrm{acc}}=(m N+a)\left(1-e^{-b N}\right),
$$

where $m$ and $a$ are, respectively, the slope and intercept of the asymptote and $b$ is a parameter controlling the curvature. Pérez et al. [29, 30] verified reliability of the above-mentioned models by fitting models with measured results of repeated load triaxial tests but found that (3) also overestimated the results for large load cycles.

To take into account the stress dependency nature of prediction models, Li and Selig [14] investigated the influence factors of parameters in (2a) and obtained the following improved model:

$$
\varepsilon_{\mathrm{acc}}=a\left(\frac{\sigma_{d}}{\sigma_{s}}\right)^{m} N^{b}
$$

in which $\sigma_{s}$ is soil static strength. For the same soil type, exponent $b$ was concluded independent of soil deviator stress and physical state. However, Korkiala-Tanttu [31] performed similar research and proposed the model as (5):

$$
\begin{aligned}
\varepsilon_{\mathrm{acc}} & =C N^{b} \frac{R}{1-R} \\
b & =d\left(\frac{q}{q_{f}}\right)+c^{\prime},
\end{aligned}
$$

where $R=q / q_{f}$ is the shear failure ratio; $q_{f}$ is the failure line in $p-q$ space; $d$ and $c^{\prime}$ are material parameters. It can be seen that the accumulation rate (curvature) of this model depends on the stress level and physical state, conflicting with the conclusions of Li and Selig.

On the other hand, in addition to those growth-type prediction models, a representative model with a stabilization prediction value may be the one proposed by Paute et al. [32] as (7), which simultaneously depicted the effects of both stress levels and number of load cycles on the buildup of permanent strain:

$$
\varepsilon_{\mathrm{acc}}=\varepsilon_{\mathrm{acc}, 100}+A\left[1-\left(\frac{N}{100}\right)^{-B}\right]
$$

in which $\varepsilon_{\text {acc, } 100}$ is the accumulated permanent axial strain during the first 100 cycles; $A$ and $B$ are regression parameters. In reality, we can see that as load cycle $N$ increases toward infinity, the limit value $A$ represents additional permanent strain for $N>100$. Thus, the authors expressed $A$ with stress states by another equation as follows:

$$
A=\frac{q_{\max } /\left(p_{\max }+p^{*}\right)}{a-b\left(q_{\max } /\left(p_{\max }+p^{*}\right)\right)},
$$

where $q_{\max }$ and $p_{\max }$ are the maximum deviator stress and maximum mean normal stress and $p^{*}$ is a stress parameter defined by intersection of the failure line and the $p$-axis. Lekarp et al. [18] and Pérez et al. [30] used this model to fit their experimental data, but they all believed that the (8) did not well represent the limit value of permanent deformation.

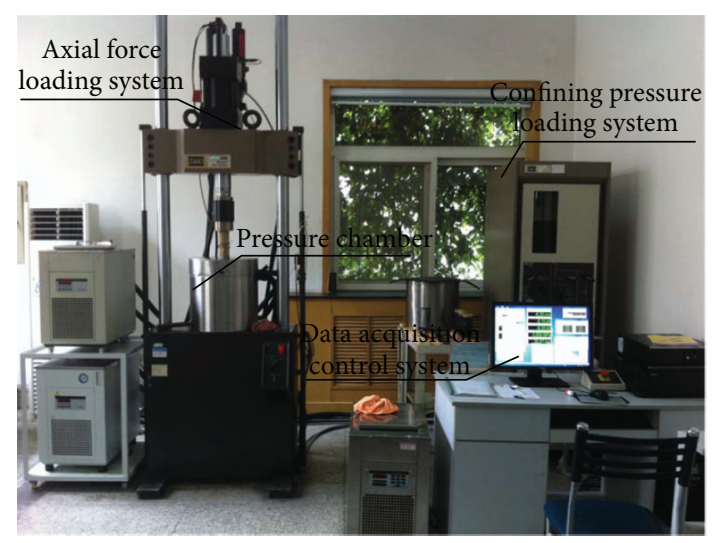

FIGURE 1: The repeated load triaxial apparatus.

\section{Cyclic Load Triaxial Test Program}

3.1. Test Equipment. In present research, all tests were carried out with the repeated load triaxial apparatus MTS-810 at State Key Laboratory of Frozen Soil Engineering of Chinese Academy of Science. Figure 1 shows the configuration of the test equipment. Both the axial load and confining pressure are applied through two sets of independent servohydraulic actuators, which can provide a maximum axial force up to $250.0 \mathrm{kN}$ and a maximum confining pressure of $20.0 \mathrm{MPa}$ on normal specimens of $61.8 \mathrm{~mm}$ in diameter and $125.0 \mathrm{~mm}$ in height. During each test, the cyclic load can be applied with a frequency range of $1 \sim 50 \mathrm{~Hz}$ employing built-in sine, triangular, and square waveforms or any other user-defined ones by means of external input. The axial deformation of specimen is measured through one linear variable differential transformer equipped on load piston of the apparatus, and the maximum scale range is $85.0 \mathrm{~mm}$ with an accuracy of $0.001 \mathrm{~mm}$. Data points sampling intervals can be set through the data acquisition and control system which is connected to the central computer. More detailed information about the apparatus can be found in [1].

3.2. Material and Sample Preparation. The coarse grained soil was carried from a project site of Batuta-Diandaigou heavy haul railway in Ordos, China. The maximum particle size of in situ soils is $40.0 \mathrm{~mm}$, with the coefficients of uniformity $\left(C_{\mathrm{u}}\right)$ and curvature $\left(C_{\mathrm{c}}\right)$ about 100 and 0.67 , respectively. According to the Code for Design on Subgrade of Railway (TB10001-2005), this material is classified as poorly graded coarse rounded gravel. However, due to the constraint of the testing device, the maximum particle size of the prepared samples should be limited to $12.3 \mathrm{~mm}$ (one-fifth of sample diameter). So before preparing the remolded samples, the equal-weight replacement method was adopted on the raw material. This method first removes the particles retained on $10.0 \mathrm{~mm}$ sieve, and then equivalent amounts of particles with grain size between $5.0 \mathrm{~mm}$ and $10.0 \mathrm{~mm}$ are mixed into the remaining soils in order to keep the same distribution for particles smaller than $5.0 \mathrm{~mm}$. The grain size distribution curves for the in situ and the modified soils are shown in 


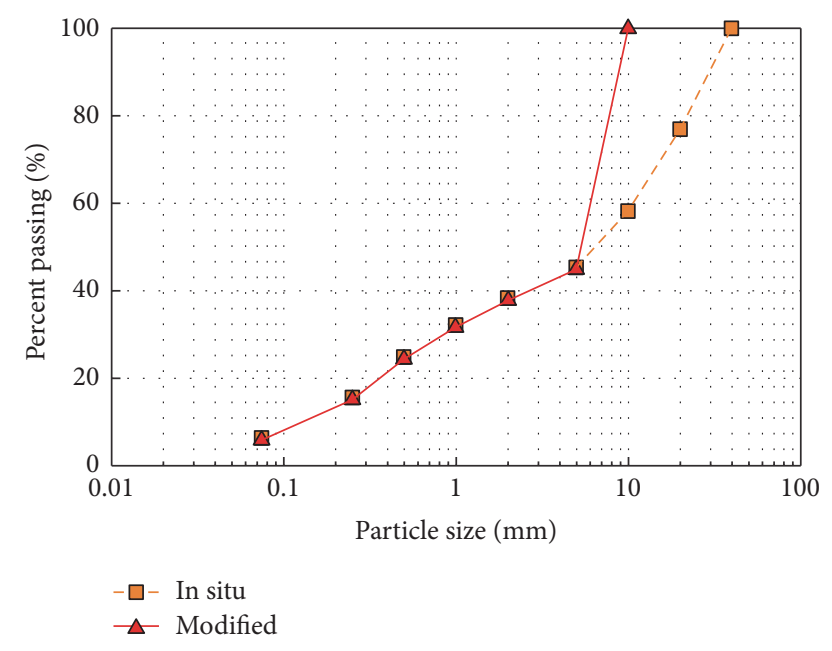

FIGURE 2: Grain size distribution of the material.

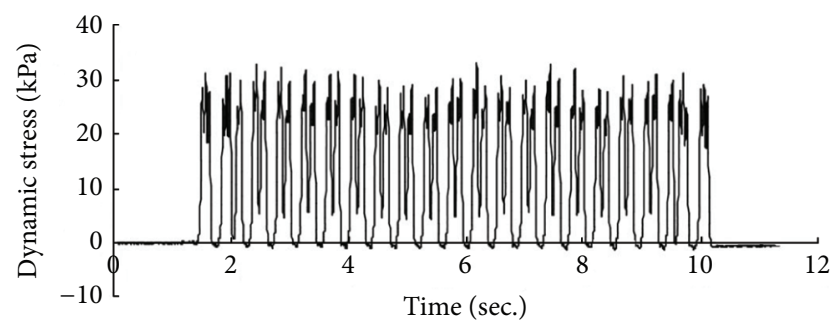

FIGURE 3: Field measurements of stress pulse wave on subgrade [25].

Figure 2. Consistent test results have been obtained using the same processing method in Lin et al. [33].

Proctor compaction tests were conducted through compact modified material into a cylindrical mold in five layers, and each layer was subjected to 25 blows with a $4.5 \mathrm{~kg}$ hammer dropped from height of $45.7 \mathrm{~cm}$. The maximum dry density and optimum moisture content of the material were $2.2 \mathrm{~g} / \mathrm{cm}^{3}$ and $6.5 \%$, respectively. Dry soil was thoroughly mixed with the required amount of water corresponding to optimum moisture content, and then the material was deposited in a sealed box for at least 12 hours to make water uniform. Five layers of compaction were carried out with the same energy as standard proctor compaction test. Specification requires that the relative compaction, which is defined by the ratio of used dry density to the maximum dry density, must be no less than 0.95 for the upper layer of subgrade. In view of the field conditions, all the specimens were compacted to the degree of 0.96 . Each specimen was packed in a membrane to keep the undrained condition during consolidation and testing period.

3.3. Cyclic Stress Waveform. Figure 3 presents a time-history of cyclic stress measured on surface layer of subgrade caused by a freight train on the Jinan-Qingdao railway running at

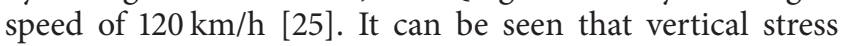
generated by prior axle of a two-axle bogie will not completely recover to the initial state before latter wheel axle arriving due

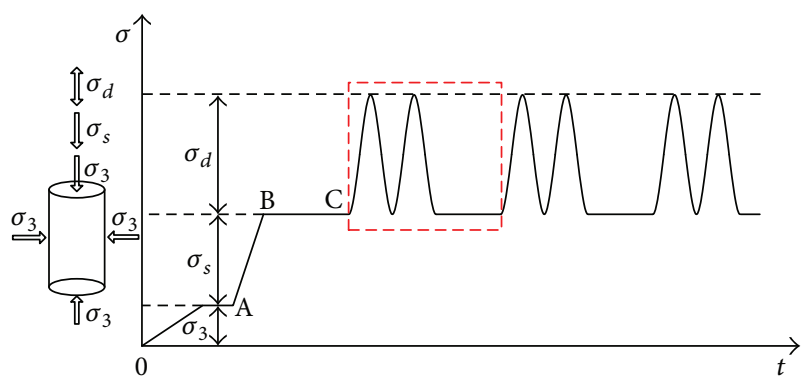

FIGURE 4: Cyclic stress loading pattern during repeated load triaxial test.

to high speed, so two adjacent axles generate two partially overlapping cyclic stress. In other words, the subgrade layer is actually subjected to a deviatoric stress consolidation state during a train passing, but the initial deviatoric stress is usually not considered in most previous experimental investigations about permanent deformation.

In this research study, a loading scheme like Figure 4 is employed to simulate the characteristic of actual dynamic wheel loads. First, the confining stress $\sigma_{3}$ and initial axial stress $\sigma_{1,0}=\sigma_{3}$ were imposed on specimens. Then, according to the predetermined initial stress ratio (controlled through the consolidation stress ratio $\left.K_{c}=\left(\sigma_{1,0}+\sigma_{s}\right) / \sigma_{3}\right)$ the axial stress was increased by $\sigma_{s}$ and held on for one hour to reach a stable initial stress state. Finally the repeated stress with amplitude $\sigma_{d}$ was imposed in the axial direction. As the rectangular dashed line shown, an intact loading period contains two repetitive haversine waves with application phase of 0.25 seconds followed by a relaxation phase of 0.5 seconds.

3.4. Test Procedure. The static strength parameters of material were determined using monotonic triaxial tests. For this purpose, four identical specimens were prepared with optimum moisture content and $96 \%$ of the maximum dry density. After isotropic consolidation period, the axial load was increased with a constant strain rate of $0.5 \%$ per minute under confining pressure levels of $0.1,0.3,0.5$, and $0.7 \mathrm{MPa}$, respectively. To high-fill embankment (generally larger than $10.0 \mathrm{~m}$ ), the selected pressure range was adequate to simulate real confining pressure conditions within the subgrade generated by a passing fully loaded train. Because of the strain-hardening process observed during these four tests, strain terminate condition was used and the axial load value was recorded as compressive strength when the axial strain reached 5.0\%.

As mentioned before, permanent deformation behavior of coarse grained soils is affected by many important factors, such as stress condition, loading frequency, duration time, and physical state. In present study, only the influences of cyclic stress amplitude, initial mean stress, and initial stress ratio are directly analyzed. The details of the loading program are shown in Table 1 and the corresponding stress paths are schematically plotted in $p-q$ plane by the mean stress $p=$ $\left(\sigma_{1}+2 \sigma_{3}\right) / 3$ and deviatoric stress $q=\sigma_{1}-\sigma_{3}$ as shown in Figure 5 . 
TABLE 1: Summary of test loading program.

\begin{tabular}{|c|c|c|c|c|}
\hline Test series & Specimen number & Consolidation stress ratio $K_{c}(-)$ & Confining pressure $\sigma_{3}(\mathrm{MPa})$ & Cyclic stress $\sigma_{d}(\mathrm{MPa})$ \\
\hline Series 1 & PD-01-PD-06 & 2.0 & 0.3 & $0.3,0.4,0.5,0.6,0.7,0.8$ \\
\hline Series 2 & PD-07-PD-11 & 2.0 & 0.5 & $0.5,0.65,0.8,0.95,1.1$ \\
\hline Series 3 & PD-12-PD-15 & 2.0 & $0.1,0.3,0.5,0.7$ & 0.5 \\
\hline \multirow{4}{*}{ Series 4} & PD-16 & \multirow{4}{*}{2.0} & 0.1 & 0.1 \\
\hline & PD-17 & & 0.3 & 0.3 \\
\hline & PD-18 & & 0.5 & 0.5 \\
\hline & PD-19 & & 0.7 & 0.7 \\
\hline \multirow{4}{*}{ Series 5} & PD-20 & 1.0 & 0.3 & \multirow{4}{*}{0.3} \\
\hline & PD-21 & 1.6 & 0.25 & \\
\hline & PD-22 & 2.0 & 0.22 & \\
\hline & PD-23 & 2.5 & 0.2 & \\
\hline \multirow{4}{*}{ Series 6} & PD-24 & 1.0 & \multirow{4}{*}{0.3} & 0.8 \\
\hline & PD-25 & 1.6 & & 0.62 \\
\hline & PD-26 & 2.0 & & 0.5 \\
\hline & PD-27 & 2.5 & & 0.35 \\
\hline
\end{tabular}

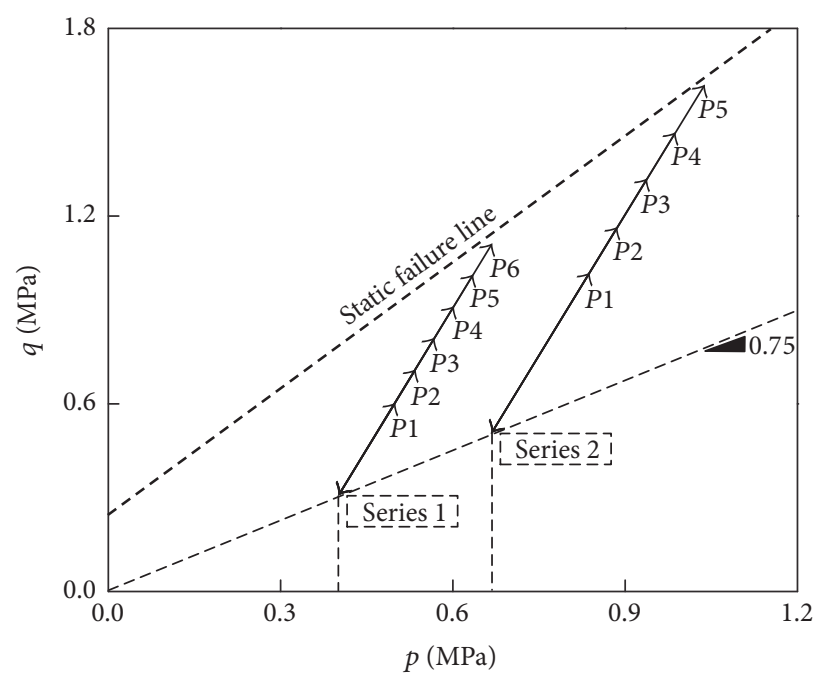

(a)

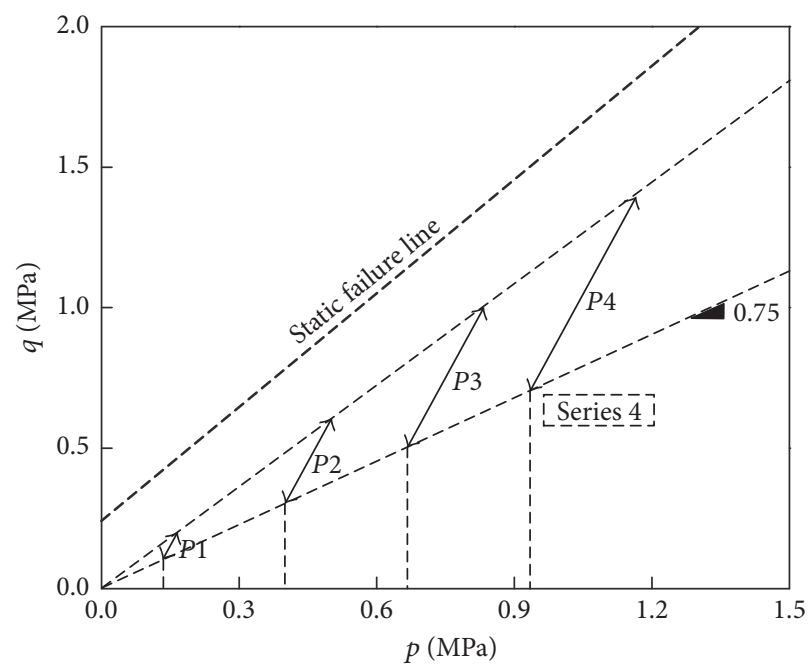

(c)

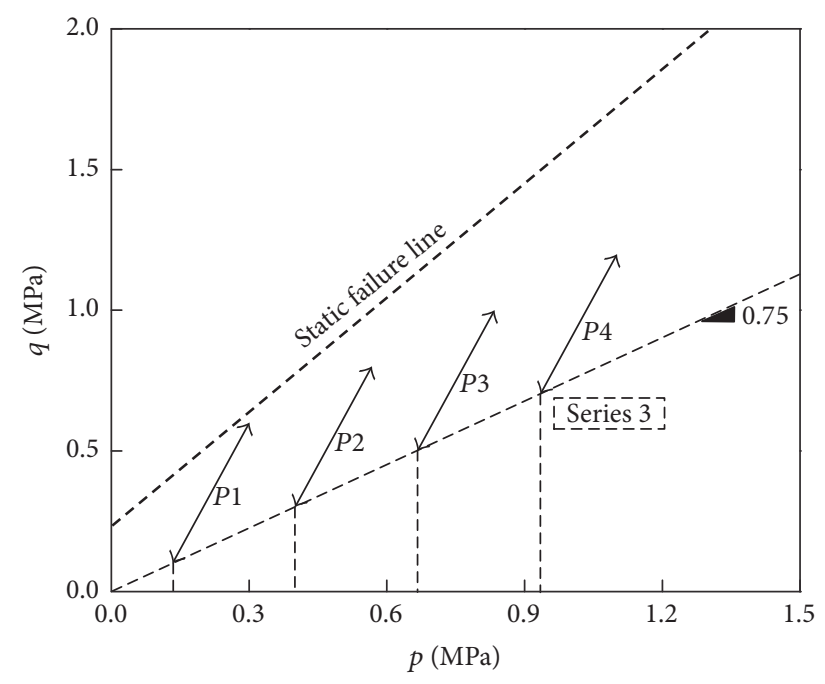

(b)

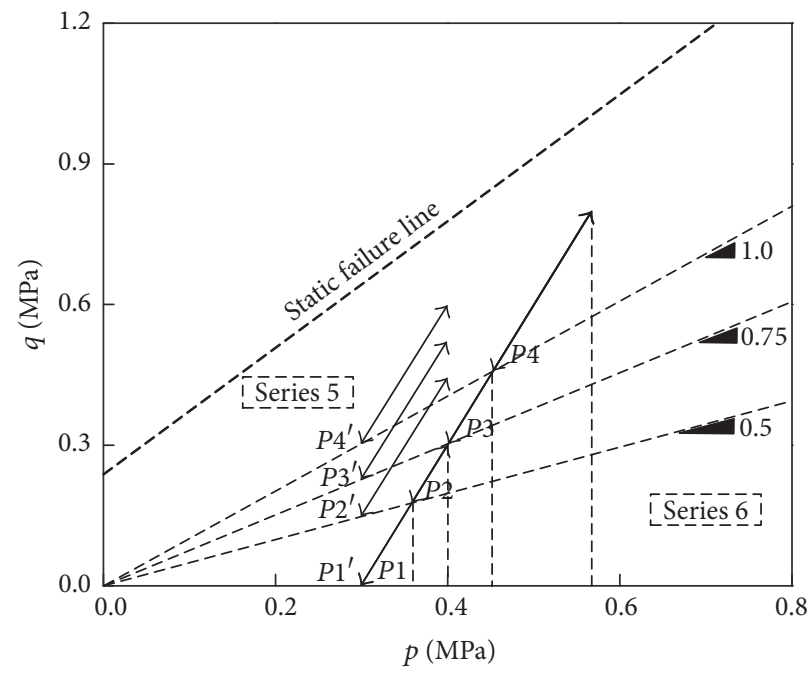

(d)

FIGURE 5: The applied stress paths in all six series of repeated load triaxial test. 
For each stress path, a new specimen was used. As can be seen in Figure 5, a total of six test series were performed. More specifically, throughout the tests of series one, series three, and series five only a single parameter (cyclic stress amplitude, initial mean stress, or initial stress ratio) was varied while the remaining parameters were kept constant, since these three series were specially designed to determine the coefficients of three independent components in the proposed permanent deformation prediction model. Moreover, test series two with confining pressure $0.5 \mathrm{MPa}$ was performed for validating the correctness of the proposed model. In order to further explore the effect of static failure line as increasing the initial mean stress, test series four modified the applied stress amplitude to make the stress ratio $\delta=q^{\text {ampl }} / p^{\text {ini }}$ constant. Finally, test series six was designed with constant values of maximum deviatoric stress $(0.8 \mathrm{MPa})$ but with different initial stress ratios, and the results were expected to verify the rationality of prediction models relating permanent deformation to the maximum deviatoric stress.

Each test was performed for up to 10,000 load cycles. The reason for this choice was to determine an analysis period compatible with laboratory test constraints and practical methods. Such an analysis method was also in accordance with the test procedure based on the shakedown concept $[24,34]$. Moreover, it was confirmed that the increase of permanent deformation became insignificant after the load cycles reaching 10,000. The test was terminated when either all loading cycles were applied or $5.0 \%$ permanent strain of the test specimen was reached. All the tests were performed under undrained conditions.

\section{Test Results and Analysis}

Based on the results of monotonic triaxial tests, the failure line is obtained according to Mohr-Coulomb failure criteria, and in this paper it is expressed as (9):

$$
\begin{aligned}
q_{\mathrm{fail}} & =M p+q_{0} \\
M & =\frac{6 \sin \varphi}{3-\sin \varphi} \\
q_{0} & =\frac{c 6 \cos \varphi}{3-\sin \varphi},
\end{aligned}
$$

where $c$ and $\varphi$ are the cohesion and friction angle; to the used coarse grained soil the values are $142.11 \mathrm{kPa}$ and $32.18^{\circ}$, respectively.

During cyclic load triaxial tests, only the axial deformation of specimen was recorded, and Figure 6 presents the development style of axial strain versus the number of load cycles. As illustrated in this figure, the strain in each load cycle can be divided into resilient and plastic strain. The resilient strain $\varepsilon_{e}$, which contains the strain in application phase $\varepsilon_{e, 1}$ and the strain in relaxation phase $\varepsilon_{e, 2}$, is calculated based on the second haversine component of an intact loading period, and the individual permanent strain $\varepsilon_{p}$ takes the average value of total residual strain in these two cycles. According to the designed test program, the permanent deformation

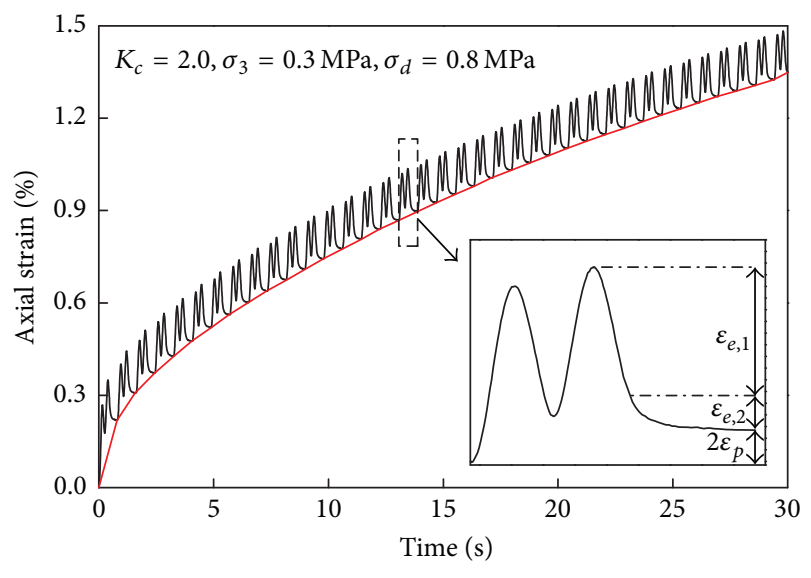

FIGURE 6: Development style of the axial deformation with loading time.

characteristics of coarse grained soil with various cyclic stress amplitude, initial mean stress, and initial stress ratio are summarized as follows.

4.1. Effect of Cyclic Stress Amplitude. Cyclic stress is an important factor that significantly affects soil dynamic behavior. Two test series with initial mean stress $p^{\text {ini }}=0.4$ and $0.67 \mathrm{MPa}$ were used to research the influence of stress amplitudes on the permanent deformation behavior of coarse grained soil. For each initial mean stress, several tests with increasing cyclic stress amplitudes were performed, and Figure 7 presents the curves of accumulated axial strain $\varepsilon_{\text {acc }}$ as a function of the number of load cycles $N$. As obvious from this figure, the total permanent strain increases with increasing cyclic stress amplitude, as well as the accumulation rates in the original period. In particular, different development styles of the data points are observed corresponding to different permanent deformation behaviors. This deformation behavior is in agreement with test results proposed by Sabine et al. [35].

As the horizontal lines shown, when relative low levels of cyclic stress are applied, or in other words less than a critical stress value (a proportion of the monotonic failure stress), the permanent strain accumulates only in the first finite number of load cycles before reaching a constant value, and thereafter the response of material becomes almost resilient. The stress-strain relationship in Figure 8 clearly presents the deformation development procedure of this type. During early stage, the hysteretic loops of two successive loading cycles do not coincide due to the residual strain, and both the shape and area vary significantly with loading repetitions. Nevertheless, the decreasing gap between the beginning and ending data points suggests that the plastic response of material is tending to cease. After the number of load cycles reaching about 1000, the shape of hysteretic loop no longer changes with increasing load cycles, and the curve of one cycle cannot be distinguished from the other one.

On the other hand, as the cyclic stress amplitude beyond a critical value, the increased stress level will crush some large particles in material and then destroy the original stable coarse aggregate skeleton by the slide between small particles, 


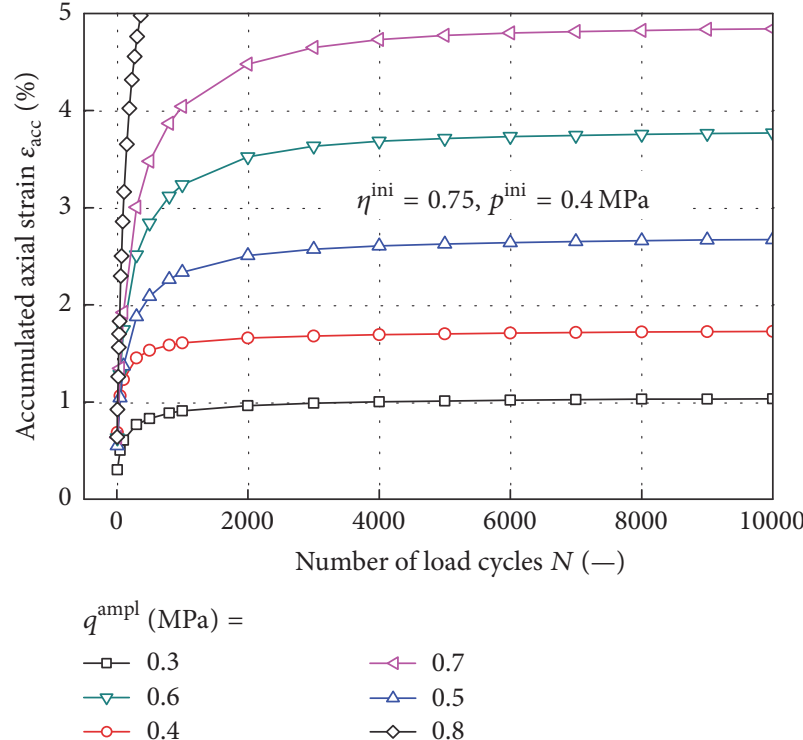

(a)

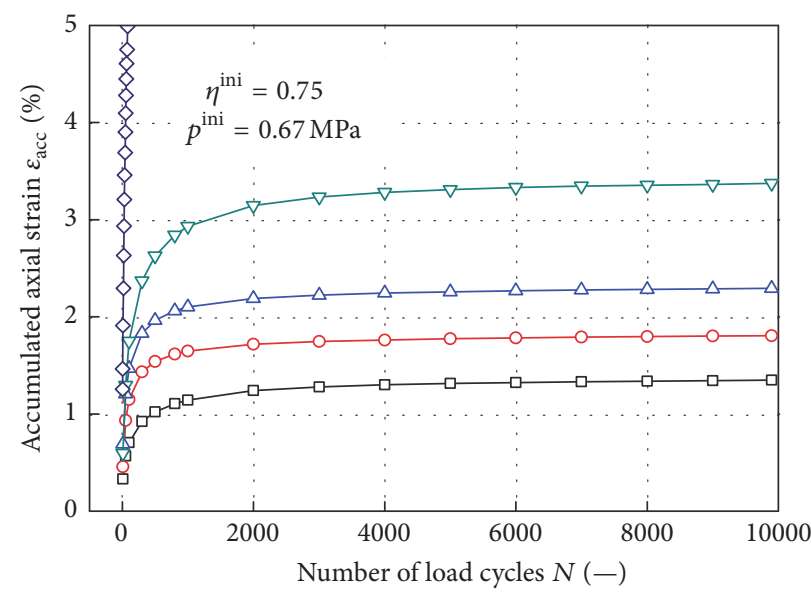

$q^{\mathrm{ampl}}(\mathrm{MPa})=$

$\begin{array}{ll}\rightarrow-0.5 & \multimap-0.65 \\ \rightarrow-0.8 & \rightarrow-0.95\end{array}$

$\multimap 1.1$

(b)

FIGURE 7: Test with different cyclic stress amplitudes; accumulated axial strain versus number of load cycles: (a) initial mean stress 0.4 MPa; (b) initial mean stress $0.67 \mathrm{MPa}$.
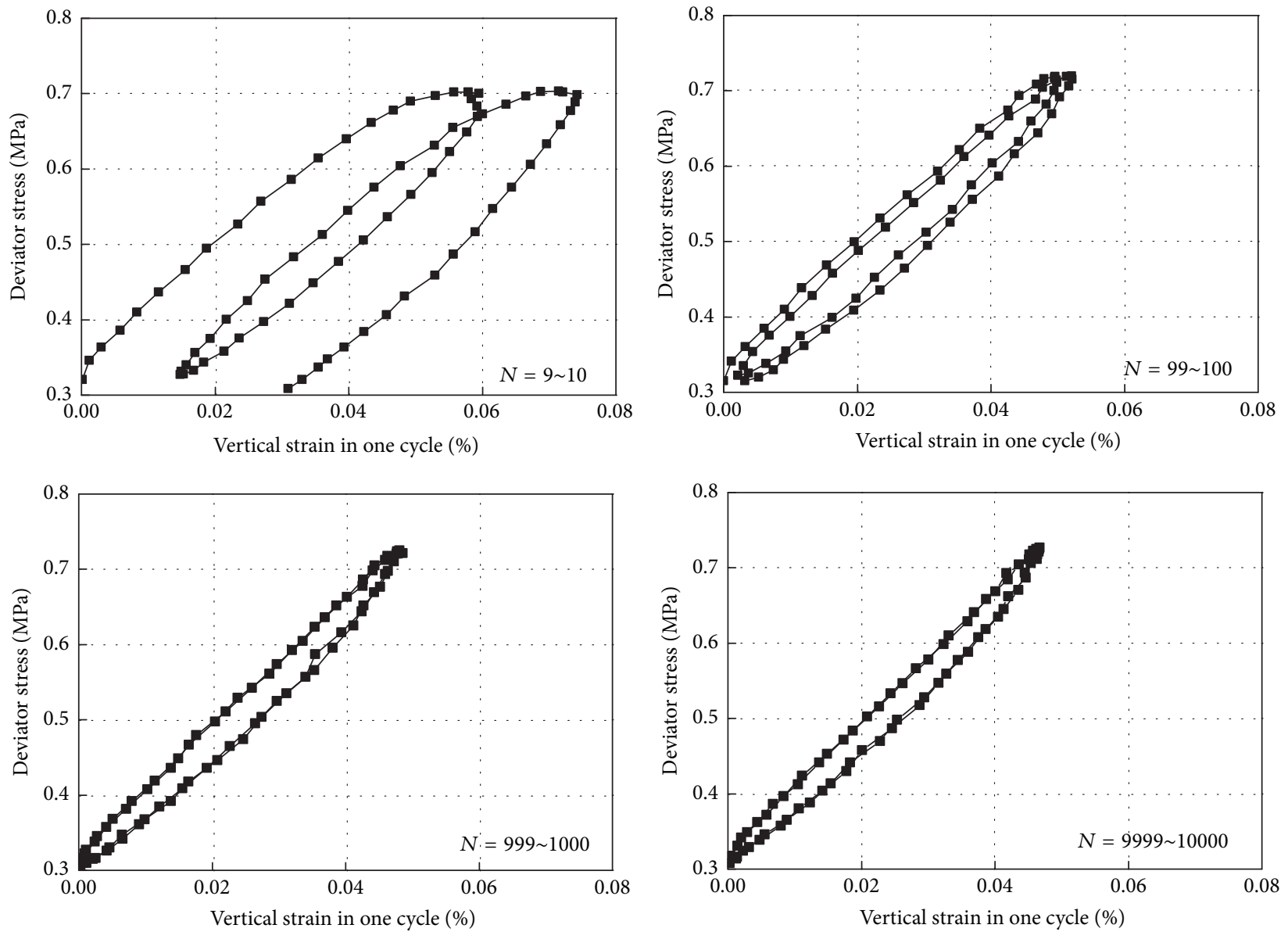

FIGURE 8: Hysteresis loops corresponding to different loading repetitions. 


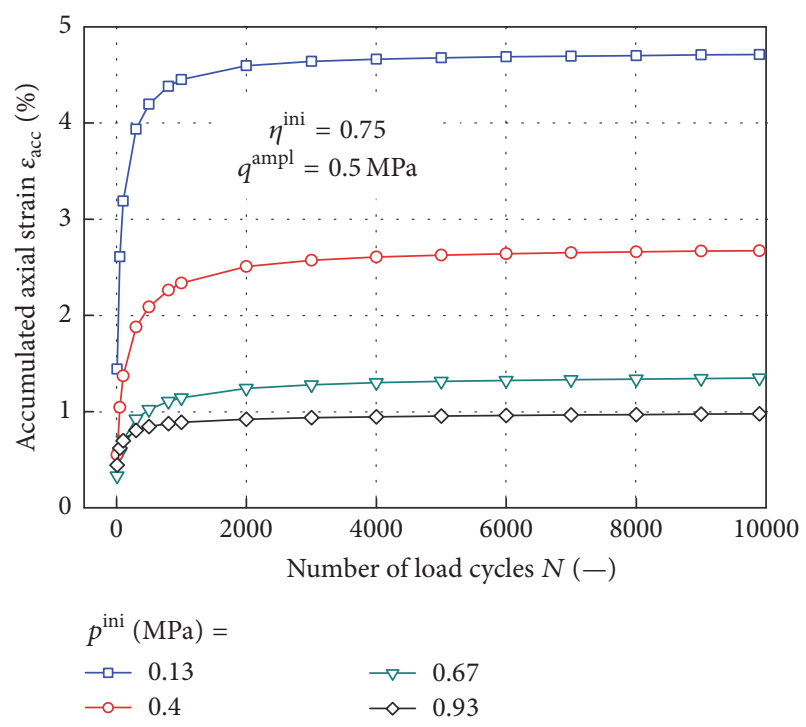

(a)

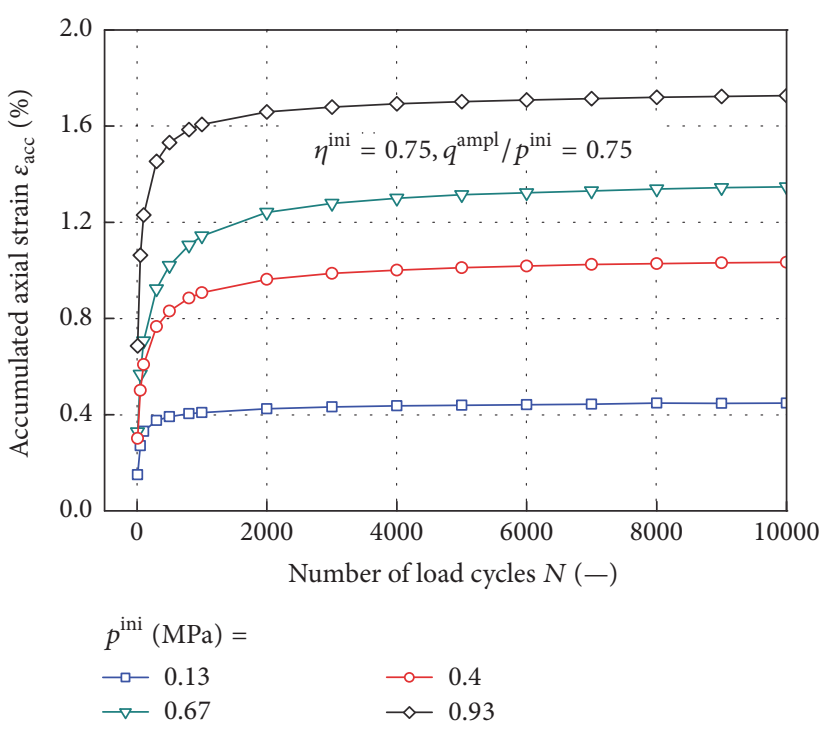

(b)

Figure 9: Test with different initial mean stress; accumulated axial strain versus number of load cycles: (a) cyclic stress amplitude $0.5 \mathrm{MPa}$; (b) $q^{\text {ampl }} / p^{\text {ini }}=0.75$.

so the axial strains accumulate rapidly with number of load cycles, do not stabilize, and quickly lead to failure, just like the vertical lines shown in the left of figure. Comparing these applied cyclic stress amplitudes with the monotonic failure stress, it can be found that cyclic loading significantly reduces the bearing capacity of coarse grained soils. For instance, under initial mean stress of $0.3 \mathrm{MPa}$ at least $12 \%$ reduction was observed. More detailed information about the failure development procedure and mechanisms can be found in other literatures [22], since the present study pays more attention to the specimens with stable deformation state.

4.2. Effect of Initial Mean Stress. The effect of the initial mean stress on the deformation development was studied in two test series with a constant initial stress ratio of $\eta^{\text {ini }}=0.75$ and $p^{\text {ini }}=0.13,0.4,0.67$, and $0.93 \mathrm{MPa}$, respectively. The measured results in terms of permanent axial strain versus number of load cycles are shown in Figure 9.

For the first test series, identical stress amplitude of $q^{\text {ampl }}=0.5 \mathrm{MPa}$ was applied, and it is apparent that the amount of permanent strain decreases with increasing initial mean stress (Figure 9(a)). The reason of this phenomenon can be attributed to that since the initial stress ratio is constant during all these four tests, higher initial mean stress corresponds to higher initial deviatoric stress as well as higher failure strength (obtained from the static failure line), but we can see that the growth rate of failure strength is faster than that of initial deviatoric stress. So even though the same stress amplitudes were applied, the largest permanent strain was obtained for the smallest initial mean stress. From this test series, we can also speculate that if the initial stress ratio $\eta^{\text {ini }}$ is equal to or exceeds the slope of static failure line, the opposite $p^{\text {ini }}$ dependence phenomenon will be observed.
On the other hand, in order to further explore the explanation about static failure strength, the stress amplitude $q^{\text {ampl }}$ was adjusted to make amplitude ratio $\delta=q^{\text {ampl }} / p^{\text {ini }}$ constant in test series four with other conditions remaining the same, and the results are presented in Figure 9(b). It was found that, opposite to the observations in first series, the largest permanent strain was obtained for the largest initial mean stress, and the same tendency was also observed for the smallest $p^{\text {ini }}$. These test results are in good accordance with the investigation of Wichtmann et al. [36] for unbound granular materials, but it is worth noting that the opposite dependence of average mean pressure $p^{\text {av }}$ (due to different cyclic stress loading method, it is similar to $p^{\text {ini }}$ in this study under the same $\eta^{\text {ini }}$ ) for sand was also reported in his work.

4.3. Effect of Initial Stress Ratio. In order to research the effect of initial stress ratio on the development of permanent deformation, two test series with $0 \leq \eta^{\text {ini }} \leq 1$ were performed, and Figure 10 presents the measured results in terms of permanent strain versus number of load cycles. It can be seen that the permanent axial strain as well as the accumulation rate increases with increasing initial stress ratio $\eta^{\text {ini }}$ when the initial mean stress $p^{\text {ini }}$ and stress amplitude $q^{\text {ampl }}$ are kept constant (Figure 10(a)). This behavior can be attributed to that because the initial mean stress is a constant value, so higher initial stress ratio denotes higher initial deviatoric stress, which reduces the bearing capacity of material before cyclic loading. Obviously, if the initial stress ratio is close to the slope of static failure line, small stress amplitude will make the specimen get failure.

Considering another loading condition as test series six, the sum of initial deviatoric stress and cyclic stress amplitude was kept constant, and then the permanent strain was observed decreasing with the initial stress ratio (Figure 10(b)). 


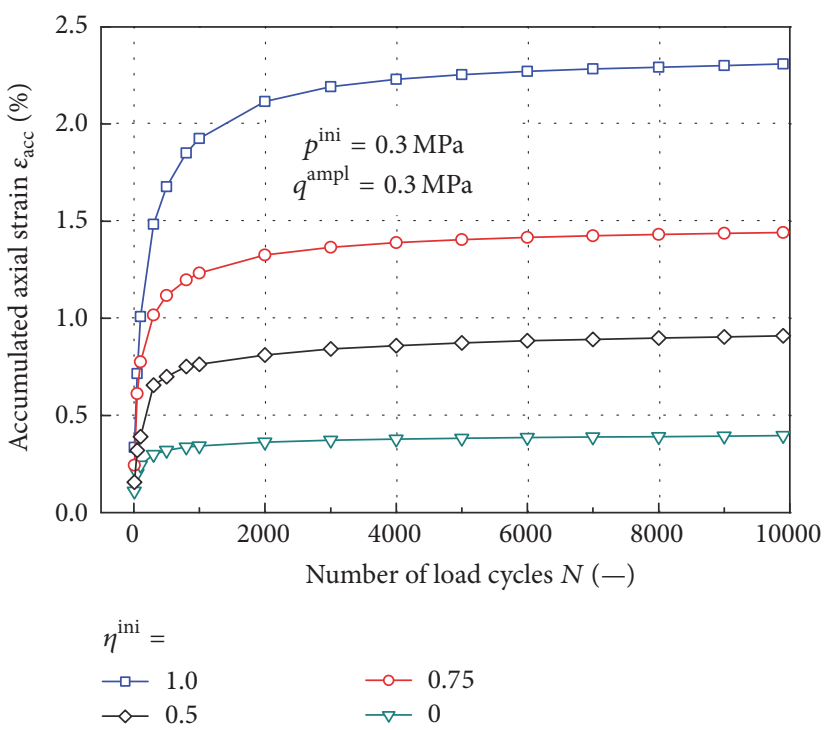

(a)
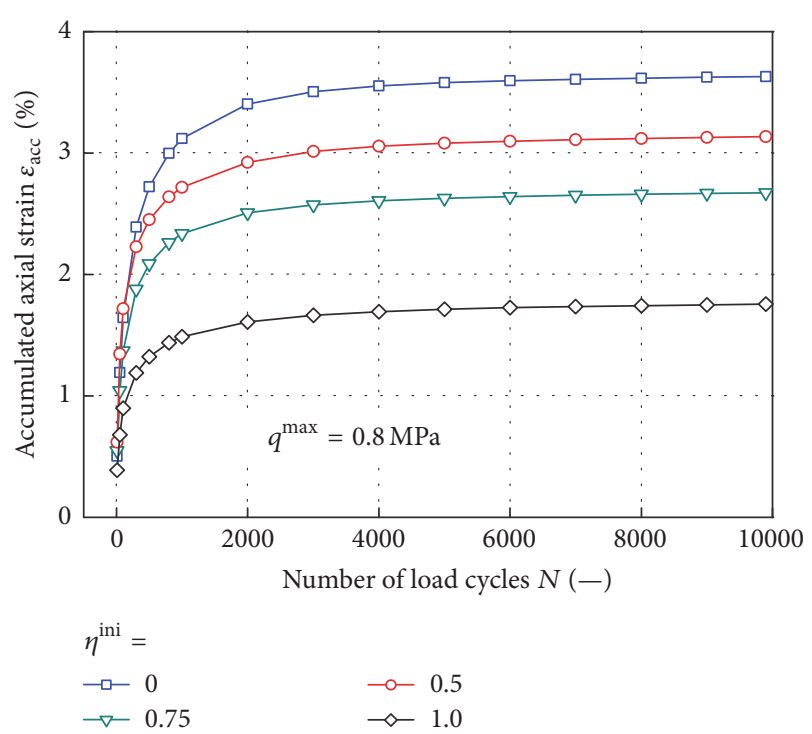

(b)

FIGURE 10: Test with different initial stress ratio; accumulated axial strain versus number of load cycles: (a) initial mean stress $0.3 \mathrm{MPa}$; (b) maximum deviatoric stress $0.8 \mathrm{MPa}$.

Moreover, higher cycle stress amplitude produced higher accumulation rate from beginning of the tests. This test result is consistent with the results obtained in some related literatures [30] and also questioned the availability of Paute's model of (8), from which the same permanent strain will be obtained as long as maximum stress is the same in the stress path.

\section{Permanent Deformation Model Development}

As mentioned before, some empirical prediction models extrapolated the permanent deformation after $N$ cycles from the residual strain $\varepsilon_{\mathrm{acc}, 1}$ after the first cycle, such as the parameter $a$ in (1), (2a), (2b), and (4). But the permanent deformation depends on so many factors that it is too complicated to lump their effects into a single parameter. For that reason, the objective of this part is to develop a simplified prediction model based on the influence rules obtained in last section, which predicts the permanent deformation accumulation with the number of load cycles by combining the influence of applied stress states.

5.1. Nonlinear Multivariable Model. In order to specify the relationships of this type, we first make the hypothesis that permanent deformation under cyclic loading can be calculated as product of four independent functions as

$$
\varepsilon_{\text {acc }}(N)=f_{\text {ampl }} f_{\eta} f_{p} f_{N} .
$$

Each function considers the influence of a different parameter. This dissociation simplifies the determination process of these functions from test results, and the validity of this method has been verified by Niemunis et al. [37].
The function $f_{\text {ampl }}$ describes the variation intensity of permanent deformation with increasing cyclic stress amplitude $q^{\text {ampl }}$. According to the results of test series one and series two, the accumulation rate of permanent deformation increases rapidly with increasing cyclic stress amplitude, especially for the paths approaching the static failure line. Therefore, a power function as (13) with material constants $C_{A 1}$ and $C_{A 2}$ is adopted to show this deformation behavior.

$$
f_{\mathrm{ampl}}=C_{A 1}\left(q^{\mathrm{ampl}}\right)^{C_{A 2}} .
$$

It is worth noting that Johnson [38] mentioned a deformation behavior so-called purely elastic, which means that the material will only undergo elastic deformation if the cyclic stress level is not beyond a certain threshold stress. However, Werkmeister et al. [34] and some other researchers $[26,39]$ all did not observe this type of deformation response during tests on granular materials. So as can be seen (13) does not consider the purely elastic behavior, meaning that any low-level cyclic stress will contribute to the accumulation of permanent deformation.

As mentioned before, under the constant stress amplitude and initial stress ratio, the increase of initial mean stress will enhance the capability of resisting deformation under cyclic loading. On the other hand, for a constant initial mean stress, the intensity of permanent strain accumulation increases with increasing initial stress ratio. These dependencies are captured by the exponential functions $f_{p}$ and $f_{\eta}$ in (14) and (15), respectively.

$$
\begin{aligned}
& f_{p}=C_{P 1} \exp \left(C_{P 2} p^{\text {ini }}\right) \\
& f_{\eta}=C_{H 1} \exp \left(C_{H 2} \eta^{\text {ini }}\right),
\end{aligned}
$$

where $C_{P 1}, C_{P 2}, C_{H 1}$, and $C_{H 2}$ are material constants. 


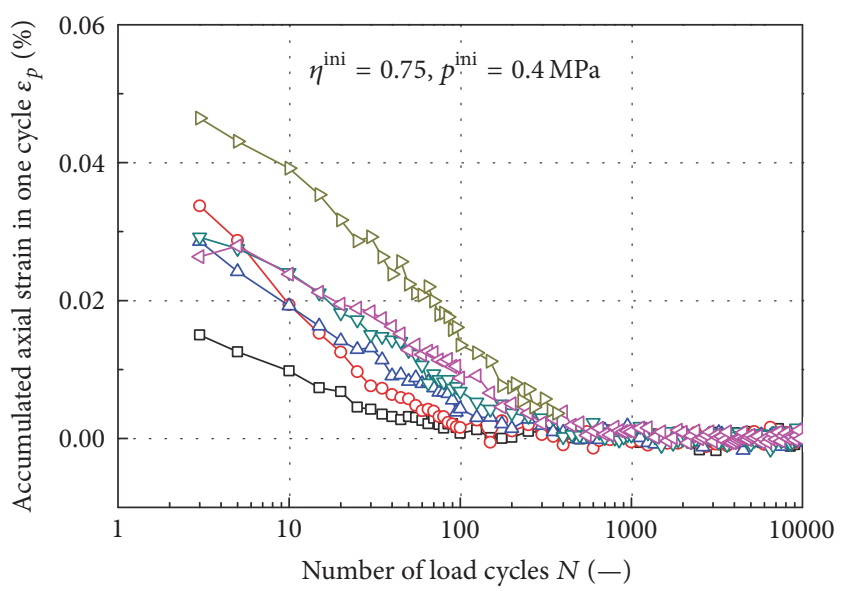

$\begin{array}{ll}q^{\mathrm{ampl}}(\mathrm{MPa})= & \\ \neg-0.3 & \rightarrow-0.6 \\ \neg-0.4 & \rightarrow \triangleleft 0.7 \\ \triangle-0.5 & \rightarrow-0.8\end{array}$

Figure 11: The development of individual permanent strain versus number of load cycles.

As well known, the rate of accumulation depends on the cyclic history; that is, if the number of cycles in the past was large then the accumulation rate is slower. According to test series one, the variation process of individual permanent strain $\varepsilon_{p}$ versus number of load cycles is depicted in Figure 11. It can be seen that the development of $\varepsilon_{p}$ can be divided into two stages according to the variation of reduction rate. Lekarp et al. [18] attributed the permanent deformation of granular materials under cyclic loading to the effects of consolidation, distortion, and attrition. In present research, since all the tests were performed under condition of nonsaturation state, the air between particles in specimen was immediately condensed as soon as imposing cyclic stress, resulting in particles rearrangement and corresponding large values of $\varepsilon_{p}$. But with the growing of stress cycles, the increased interparticle contact area gradually reduced the contact stress and further prevented relative movement between particles. So, as the initial approximate straight line shown in Figure 11, the dynamic consolidation contributed most to the rapid decline of individual permanent strain. While turning into the other deformation stage, the reduction rate of $\varepsilon_{p}$ began to decrease and eventually leveled off. At this point, it seems that the increment of permanent strain to each cycle of loading derived from shear deformations, which were more likely the results of limited unrecoverable particle reorientation and contact attrition.

Therefore, in order to well reflect the deformation variation trend with number of load cycles, the function $f_{N}$ is proposed as (16) containing two simultaneous components, rapid dynamic compaction procedure, and relatively slow shear deformation.

$$
f_{N}=C_{N 1}\left[1-\exp \left(-C_{N 2} N\right)\right]+C_{N 3}\left(1-N^{-C_{N 4}}\right) \text {. }
$$

From (16) we can see that in the beginning specimen is subjected to combined effect of dynamic compaction and shear deformation, so the axial strain accumulates rapidly. After a certain number of load cycles, however, the exponential function term first goes toward a limit value, indicating the end of dynamic compaction stage. Hereafter, the accumulated deformation rate reduces significantly, and finally the second term will give an asymptotic value as $N$ increases toward infinity.

5.2. Material Parameters. For estimating cumulative plastic strain by (12), iterative analysis method is adopted to obtain the values of these material constants, and the detailed procedure can be summarized as follows.

(1) Determine Initial Functions for the Iterative Analysis. For test series one, permanent axial strain corresponding to $N=50,100,500,1000,5000$, and 10000 from all the stabilized stress paths is fitted to (13) with nonlinear least square method, and the obtained stress amplitude function is denoted as $f_{\text {ampl, },}$. Different load cycles here are selected to remove the effect of $N$, and the range used in this paper gives satisfactory performance. In the same way, initial stress ratio function $f_{\eta, 0}$ and initial mean stress function $f_{p, 0}$ are obtained from test series three and series five, respectively.

(2) Iterative Procedure to Determine Material Constants $C_{N 1}$, $C_{N 2}, C_{N 3}$, and $C_{N 4}$. Experimental results from all the stress paths in test series one, series three, and series five are divided by functions $f_{\mathrm{ampl}, D}, f_{\eta, D}$, and $f_{p, D}$ to capture the pure $N$ dependence of the permanent axial strain, and the normalized permanent axial strain is fitted to (16) denoted as $f_{N, D}$. Here the subscript $D$ denotes the number of iterations, which equals zero for initial stage.

(3) Iterative Procedure to Determine Material Constants $C_{A 1}$, $C_{A 2}, C_{P 1}, C_{P 2}, C_{H 1}$, and $C_{H 2}$. For test series one, permanent axial strain at $N=50,100,500,1000,5000$, and 10000 is divided by functions $f_{\eta, D}$ and $f_{p, D}$ and the corresponding values of $f_{N, D}$ at different $N$; this generates a more refined stress amplitude function $f_{\text {ampl, } D+1}$. Stress ratio function $f_{\eta, D+1}$ and mean stress function $f_{p, D+1}$ are obtained from test series three and series five, respectively.

(4) Stopping Criterion for Iteration. If the variation of all parameters is less than $1.0 \%$, the iteration process will be terminated; otherwise, go back to step (2).

According to the process presented above, the normalized permanent axial strain versus cyclic stress amplitude, initial mean stress, initial stress ratio, and number of load cycles are shown in Figures 12-15, respectively. As can be seen the normalized data fall together into a relative narrow band, and the parameters corresponding to the curves presented as solid lines are shown in Table 2.

5.3. Model Validation and Evaluation. Test series two and series four, which are not used during the establishment of the prediction model, are used to verify the reliability of the model proposed in this paper, and the measured results and predicted ones are depicted in Figures 16(a) and 16(b). From these figures it can be seen that although the 


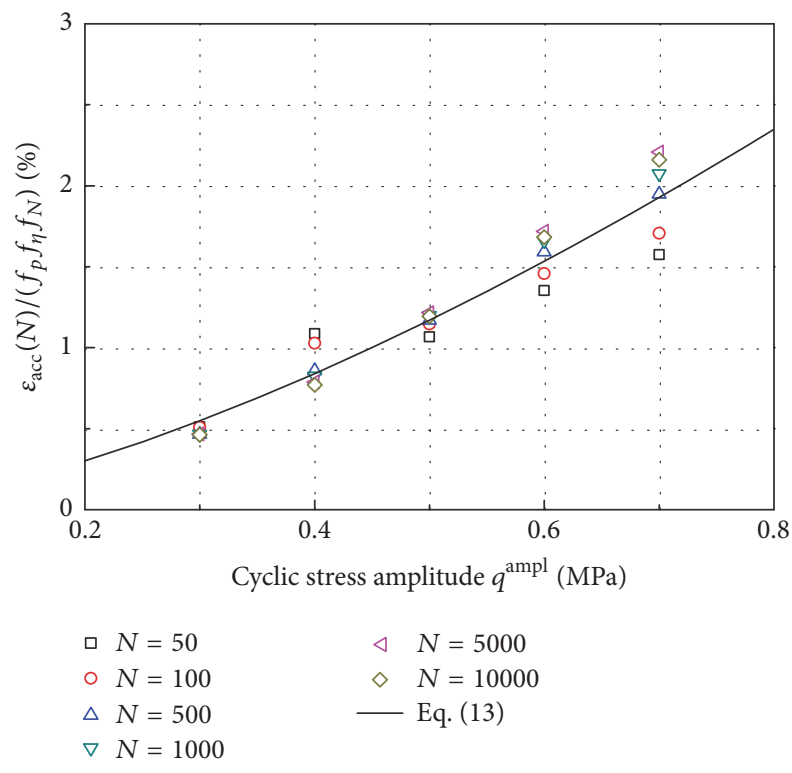

FIGURE 12: Normalized accumulated axial strain versus cyclic stress amplitude.

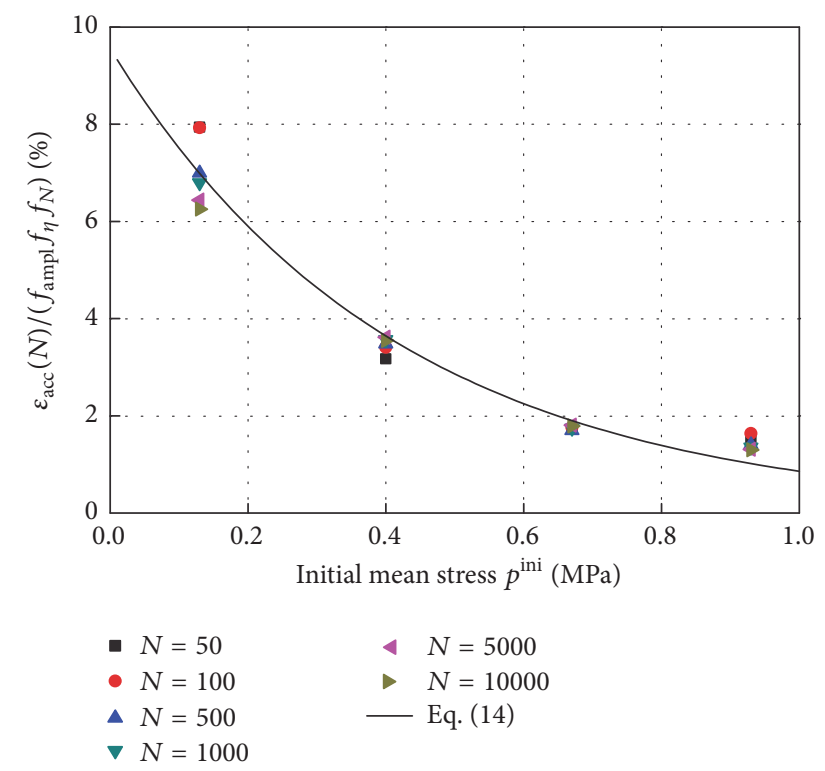

FIGURE 13: Normalized accumulated axial strain versus initial mean stress.

simulated permanent deformation values will more or less fluctuate around the measured results, the predicted trends of permanent strain with load cycles agree reasonably well with the test trends. In addition, the prediction values of other four test series are shown in Figures 16(c)-16(f).

As shown in Figures $16(\mathrm{~g})$ and $16(\mathrm{~h})$, the most widely used Barksdale model and Monismith model are also used to directly fit the test data for comparison purpose. It is found that within the tested loading number $(N=10000)$, despite the fact that small deviation is observed during the initial loading period, these two models also give good predictions. However, an efficient and practical prediction model for

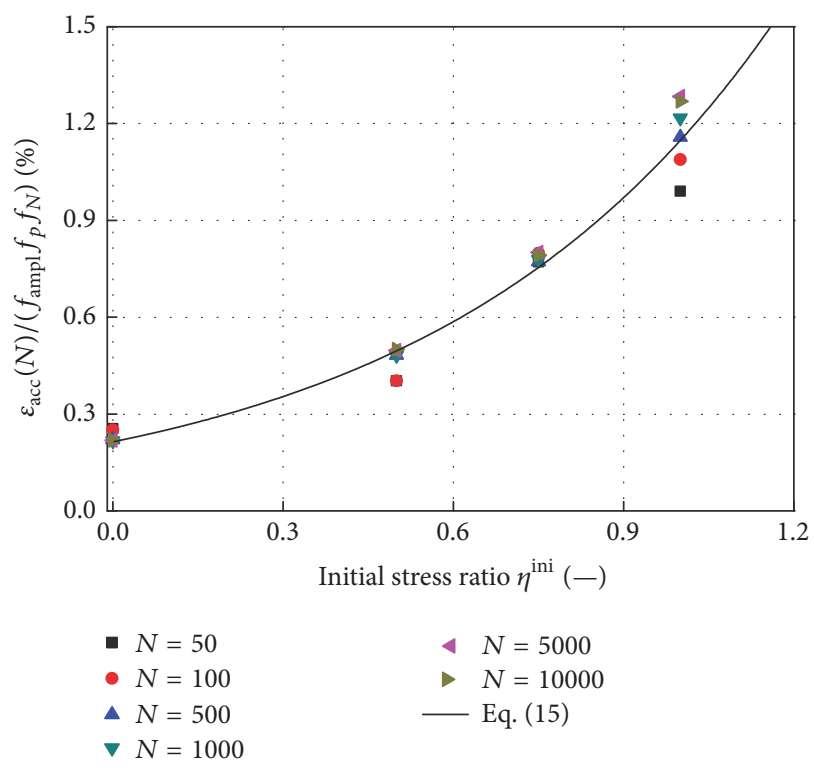

FIGURE 14: Normalized accumulated axial strain versus initial stress ratio.



FIGURE 15: Normalized accumulated axial strain versus number of load cycles.

permanent strain should not only well fit the test results, but also exactly predict the long-term deformation of the material. Therefore, the model-predicting values up to $1 \times 10^{5}$ load cycles are also presented in Figure 16. As observed, values from (1) and (2a) all keep increasing with the application of the load, without an asymptotic value, especially for the conditions of large permanent strain. In other words, failure will be reached as long as the load cycles are large enough, no matter how low the levels of the applied cyclic stress are. Obviously, it is contradicted with the phenomena observed in present tests and the shakedown theory, so it seems not suitable for the coarse grained soils used here. In contrast, the composition of (16) makes it reach a limit value as $N$ increases 

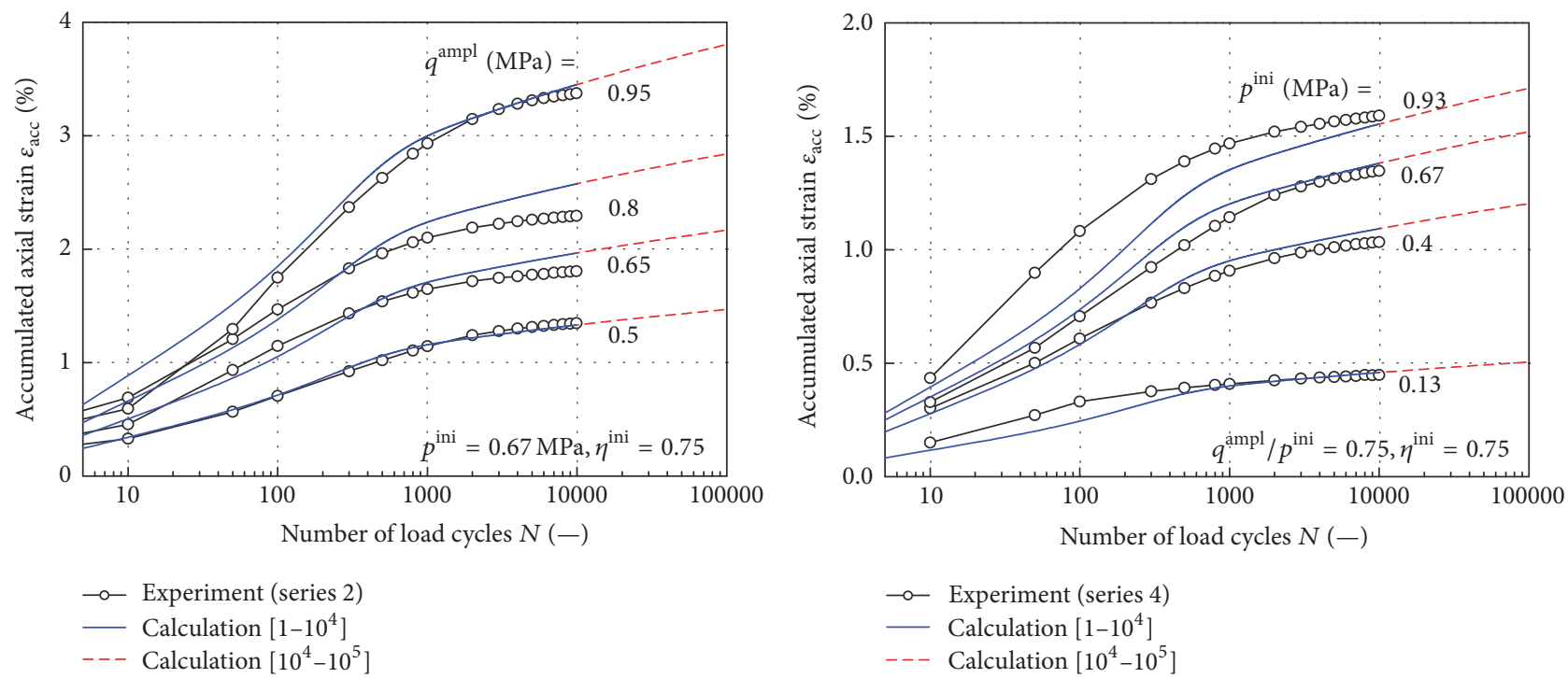

(a)
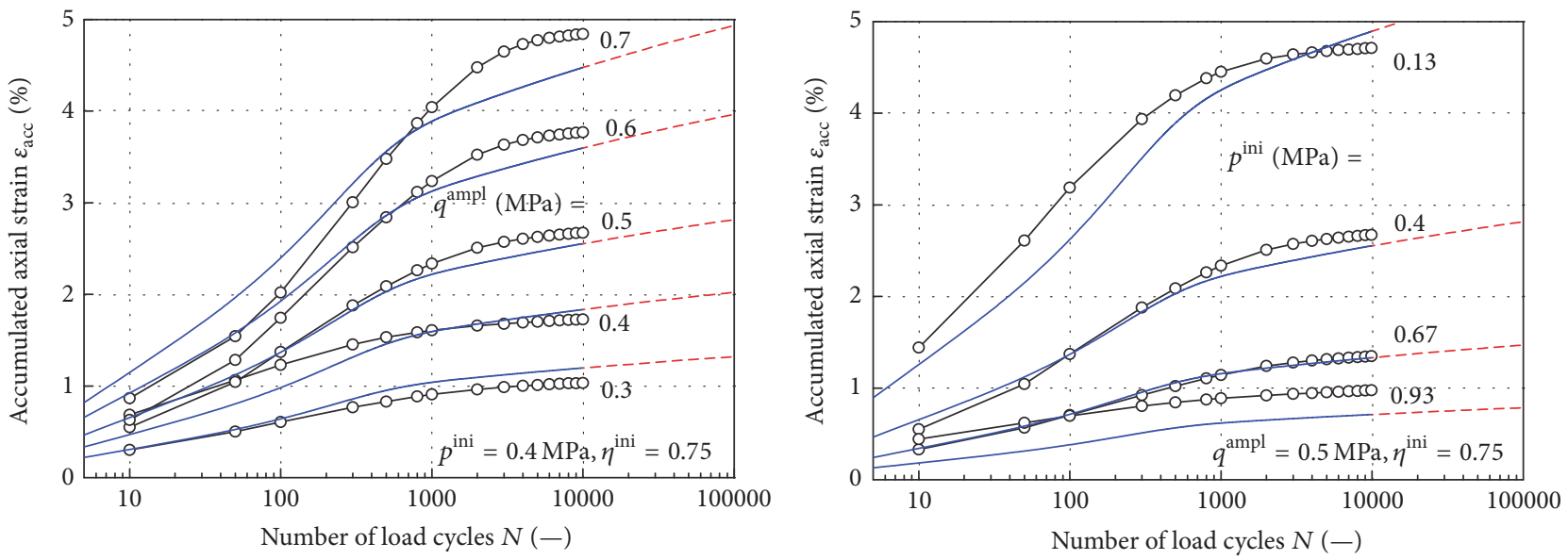

- - Experiment (series 1)

Calculation $\left[1-10^{4}\right]$

--- Calculation $\left[10^{4}-10^{5}\right]$

$\multimap$ Experiment (series 3 )

- Calculation $\left[1-10^{4}\right]$

--- Calculation $\left[10^{4}-10^{5}\right]$

(c)

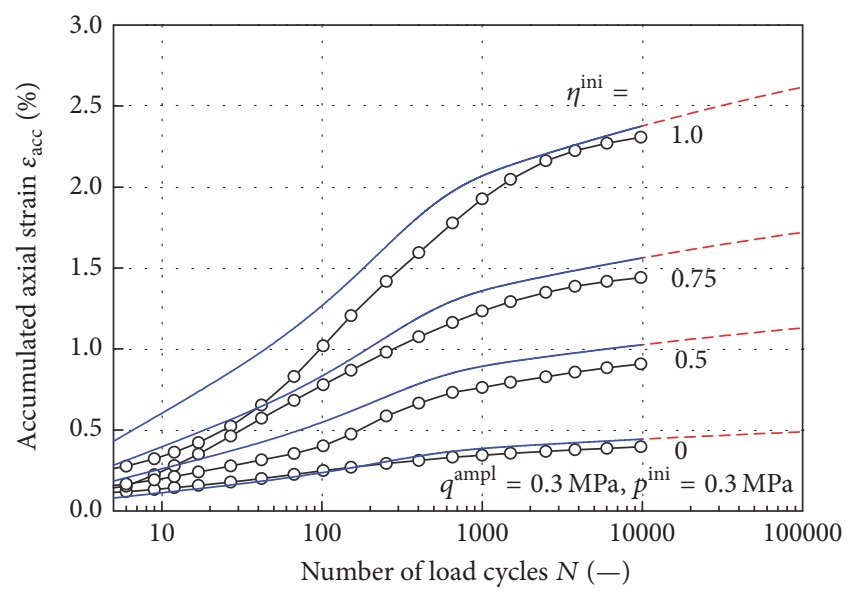

(d)

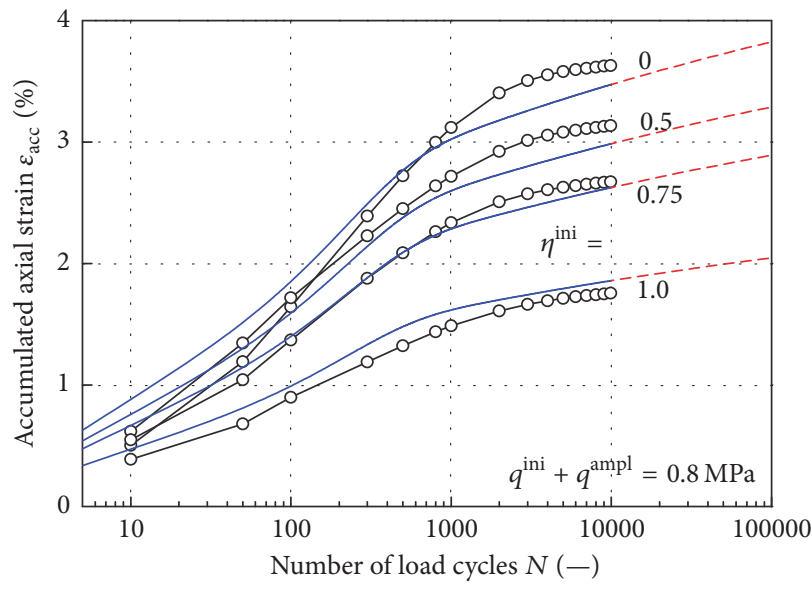

$\multimap$ Experiment (series 5)

- Calculation $\left[1-10^{4}\right]$

--- Calculation $\left[10^{4}-10^{5}\right]$

$\multimap$ Experiment (series 6)

- Calculation $\left[1-10^{4}\right]$

--- Calculation $\left[10^{4}-10^{5}\right]$

(e)

FIGURE 16: Continued. 


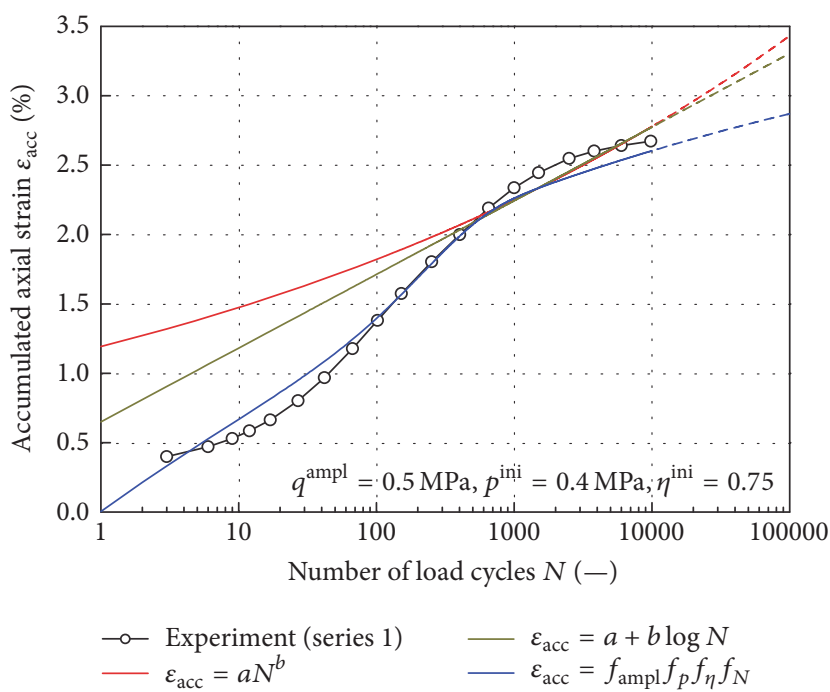

(g)

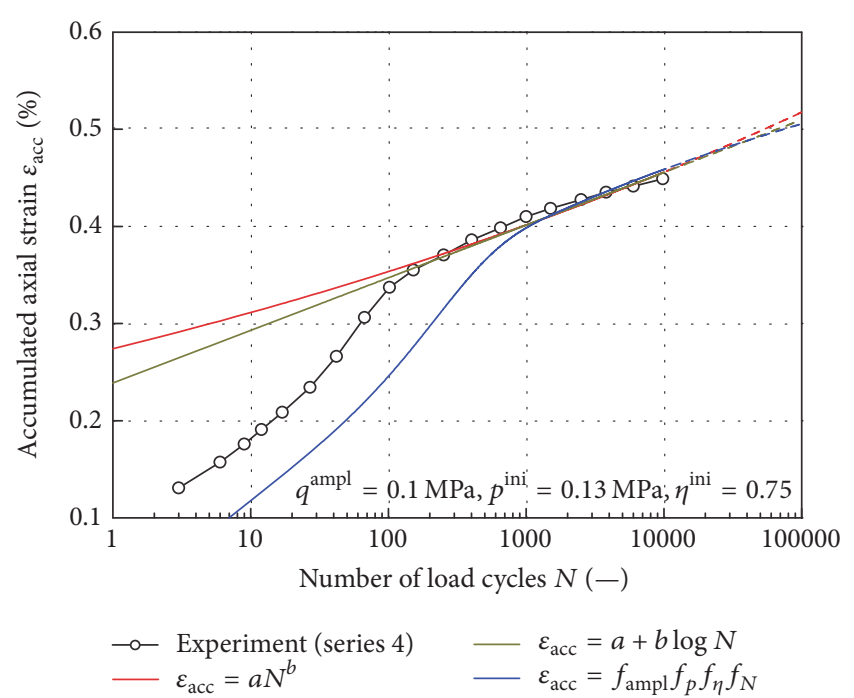

(h)

FIGURE 16: Comparison of the calculated and measured accumulated axial strain.

TABLE 2: Summary of the material constants.

\begin{tabular}{lcc}
\hline Function & Constant & Value \\
\hline$f_{\text {ampl }}=C_{A 1}\left(q^{\text {ampl }}\right)^{C_{A 2}}$ & $C_{A 1}$ & 3.27 \\
\hline \multirow{2}{*}{$f_{p}=C_{P 1} \exp \left(C_{P 2} p^{\text {ini }}\right)$} & $C_{A 2}$ & 1.48 \\
\hline \multirow{2}{*}{$f_{\eta}=C_{H 1} \exp \left(C_{H 2} \eta^{\text {ini }}\right)$} & $C_{P 1}$ & 9.56 \\
& $C_{P 2}$ & -2.41 \\
\hline \multirow{2}{*}{$f_{N}=C_{N 1}\left[1-\exp \left(-C_{N 2} N\right)\right]+C_{N 3}\left(1-N^{-C_{N 4}}\right)$} & $C_{H 1}$ & 0.21 \\
& $C_{H 2}$ & 1.68 \\
\hline & $C_{N 1}$ & 0.22 \\
& $C_{N 3}$ & 0.004 \\
& $C_{N 4}$ & 0.01 \\
\end{tabular}

to infinity, presenting a more reasonable development trend for long-term deformation prediction.

Of course, there are still some shortcomings in this empirical model; for example, it cannot reflect the influence of soil type, moisture content, and grain size distribution. More importantly, the case that the initial stress ratio is equal to or larger than the slope of static failure line is not taken into account in the model; these problems will be gradually investigated in the future.

\section{Conclusions}

This paper presents the results of a laboratory investigation aimed at analyzing the permanent deformation behavior of coarse grained subgrade soils under train-induced cyclic loading; the effects of the cyclic stress amplitude, initial mean stress, and initial stress ratio are researched, and from the results of this research the following conclusions may be drawn:
(1) Under repeated loading, the permanent deformation of coarse grained soils increases with increasing cyclic stress amplitude. Compared to static failure strength, cyclic loading reduces the bearing capacity of specimens. In particular, when subjected to low cyclic stress levels, the residual deformation in each cycle decreases progressively with the number of cycles, and the specimen eventually reaches an equilibrium state with only resilient deformation. But once the cyclic stress level is beyond a critical value, the axial deformation increases rapidly and gets failure. The response of purely elastic is not observed in coarse grained soils.

(2) As the initial mean stress is kept constant, the initial stress ratio will obviously facilitate the buildup of axial deformation since it is corresponding to higher deviatoric stress. On the other hand, if the maximum deviatoric stress is kept constant, then the permanent deformation will decrease with increasing initial stress ratio.

(3) If the initial stress ratio was less than the slope of static failure line, then the growth rate of failure strength is faster than that of initial deviatoric stress, so the increase of initial mean stress will enhance the capability of resisting deformation.

(4) For coarse grained soils, a two-stage model can better reflect the development trend of deformation. A simplified permanent deformation model, which takes into account the influences of the cyclic stress amplitude, initial mean stress, initial stress ratio, and number of load cycles as four independent functions, gives satisfactory prediction values of permanent deformation.

All the tests during this research are carried out with optimum moisture content and $96 \%$ of maximum dry density, 
with initial mean stress $0.13 \leq p^{\text {ini }} \leq 0.93$ and initial stress ratio $0 \leq \eta^{\text {ini }} \leq 1.0$, so the parameter values obtained in this paper are valid under similar conditions with these tests. For other conditions and factors, such as grain size distribution and void ratio, more tests should be performed.

\section{Competing Interests}

The authors declare that there is no conflict of interests regarding the publication of this paper.

\section{Acknowledgments}

The authors are grateful to the State Key Laboratory of Frozen Soils Engineering of China for the test support. And the work obtained support from the following agents: the National Natural Science Foundation of China (Grant no. 51174261), Key Program of the National Natural Science Foundation of China (Grant no. 41430634), and China Shenhua Energy Company Limited (201212240384).

\section{References}

[1] A. J. Puppala, L. N. Mohammad, and A. Allen, "Permanent deformation characterization of subgrade soils from RLT test," Journal of Materials in Civil Engineering, vol. 11, no. 4, pp. 274282, 1999.

[2] F. Lekarp, U. Isacsson, and A. Dawson, "State of the art. I: resilient response of unbound aggregates," Journal of Transportation Engineering, vol. 126, no. 1, pp. 66-75, 2000.

[3] C. Chazallon, P. Hornych, and S. Mouhoubi, "Elastoplastic model for the long-term behavior modeling of unbound granular materials in flexible pavements," International Journal of Geomechanics, vol. 6, no. 4, pp. 279-289, 2006.

[4] M.-C. Weng, B.-L. Chu, and Y.-L. Ho, "Elastoplastic deformation characteristics of gravelly soils," Journal of Geotechnical and Geoenvironmental Engineering, vol. 139, no. 6, pp. 947-955, 2013.

[5] M. Zaman, D.-H. Chen, and J. Laguros, "Resilient moduli of granular materials," Journal of Transportation Engineering, vol. 120, no. 6, pp. 967-988, 1994.

[6] D. Assimaki, E. Kausel, and A. Whittle, "Model for dynamic shear modulus and damping for granular soils," Journal of Geotechnical and Geoenvironmental Engineering, vol. 126, no. 10, pp. 859-869, 2000.

[7] J. Lee, J. Kim, and B. Kang, "Normalized resilient modulus model for subbase and subgrade based on stress-dependent modulus degradation," Journal of Transportation Engineering, vol. 135, no. 9, pp. 600-610, 2009.

[8] N. H. Thom, Design of road foundations [Ph.D. thesis], Department of Civil Engineering, University of Nottingham, Nottingham, UK, 1988.

[9] H. B. Seed, R. T. Wong, I. M. Idriss, and K. Tokimatsu, "Moduli and damping factors for dynamic analyses of cohesionless soils," Journal of Geotechnical Engineering, vol. 112, no. 11, pp. 10161032, 1986.

[10] F. Lekarp, U. Isacsson, and A. Dawson, "State of the art. II: permanent strain response of unbound aggregates," Journal of Transportation Engineering, vol. 126, no. 1, pp. 76-83, 2000.
[11] H. Soliman and A. Shalaby, "Permanent deformation behavior of unbound granular base materials with varying moisture and fines content," Transportation Geotechnics, vol. 4, pp. 1-12, 2015.

[12] A. Lashine, S. Brown, and P. Pell, Dynamic Properties of Soils, Department of Civil Engineering, University of Nottingham, Nottingham, UK, 1971.

[13] R. W. Lentz and G. Y. Baladi, "Constitutive equation for permanent strain of sand subjected to cyclic loading," Transportation Research Record, vol. 810, pp. 50-54, 1981.

[14] D. Li and E. T. Selig, "Cumulative plastic deformation for finegrained subgrade soils," Journal of Geotechnical Engineering, vol. 122, no. 12, Article ID 11784, pp. 1006-1013, 1996.

[15] L. C. Chow, Permanent deformation behavior of unbound granular materials and rutting model development [M.S. thesis], University of Illinois at Urbana-Champaign, 2014.

[16] G. P. Raymond and D. R. Williams, "Repeated load triaxial tests on a dolomite ballast," Journal of the Geotechnical Engineering Division, vol. 104, no. 7, pp. 1013-1029, 1978.

[17] J. W. Pappin, Characteristics of a granular material for pavement analysis [Ph.D. thesis], University of Nottingham, Nottingham, UK, 1979.

[18] F. Lekarp, I. R. Richardson, and A. Dawson, "Influences on permanent deformation behavior of unbound granular materials," Transportation Research Record, no. 1547, pp. 68-75, 1996.

[19] J. Morgan, The Response of Granular Materials to Repeated Loading, Australian Road Research Board Proc, 1966.

[20] R. D. Barksdale, "Laboratory evaluation of rutting in base course materials," in Proceedings of the 3rd International Conference on the Structural Design of Asphalt Pavements, London, UK, September 1972.

[21] G. T. H. Sweere, Unbound Granular Bases for Roads, TU Delft, Delft University of Technology, Delft, The Netherlands, 1990.

[22] S. Werkmeister, A. R. Dawson, and F. Wellner, "Permanent deformation behaviour of granular materials," Road Materials and Pavement Design, vol. 6, no. 1, pp. 31-51, 2005.

[23] G. Cerni, F. Cardone, and M. Bocci, "Permanent deformation behaviour of unbound recycled mixtures," Construction and Building Materials, vol. 37, pp. 573-580, 2012.

[24] G. Cerni, F. Cardone, A. Virgili, and S. Camilli, "Characterisation of permanent deformation behaviour of unbound granular materials under repeated triaxial loading," Construction and Building Materials, vol. 28, no. 1, pp. 79-87, 2012.

[25] J. Liu and J. Xiao, "Experimental study on the stability of railroad silt subgrade with increasing train speed," Journal of Geotechnical and Geoenvironmental Engineering, vol. 136, no. 6, pp. 833-841, 2010.

[26] P. Hornych and A. El Abd, "Selection and evaluation of models for prediction of permanent deformations of unbound granular materials in road pavements," Work Package 5, 2004.

[27] C. L. Monismith, N. Ogawa, and C. R. Freeme, "Permanent deformation characteristics of subgrade soils due to repeated loading," Transportation Research Record, no. 537, pp. 1-17, 1975.

[28] H. Wolff and A. T. Visser, "Incorporating elasto-plasticity in granular layer pavement design," Proceedings of the Institution of Civil Engineers-Transport, vol. 105, no. 4, pp. 259-272, 1994.

[29] I. Pérez, L. Medina, and M. G. Romana, "Permanent deformation models for a granular material used in road pavements," Construction and Building Materials, vol. 20, no. 9, pp. 790-800, 2006.

[30] I. Pérez and J. Gallego, "Rutting prediction of a granular material for base layers of low-traffic roads," Construction and Building Materials, vol. 24, no. 3, pp. 340-345, 2010. 
[31] L. Korkiala-Tanttu, "Verification of rutting calculation for unbound road materials," Proceedings of the Institution of Civil Engineers: Transport, vol. 162, no. 2, pp. 107-114, 2009.

[32] J. Paute, P. Hornych, and J. Benaben, "Repeated load triaxial testing of granular materials in the French Network of Laboratories des Ponts et Chaussées," in Flexible Pavements. Proceedings of the European Symposium Euroflex 1993 Held in Lisbon, Portugal, 20-22 September 1993, 1996.

[33] S.-Y. Lin, P. S. Lin, H.-S. Luo, and C. Hsein Juang, "Shear modulus and damping ratio characteristics of gravelly deposits," Canadian Geotechnical Journal, vol. 37, no. 3, pp. 638-651, 2000.

[34] S. Werkmeister, A. R. Dawson, and F. Wellner, "Permanent deformation behavior of granular materials and the shakedown concept," Transportation Research Record, no. 1757, pp. 75-81, 2001.

[35] W. Sabine, N. Ralf, A. Dawson, and W. Frohmut, "Deformation behaviour of granular materials under repeated dynamic load," Journal of Environmental Geomechanics, pp. 215-223, 2002.

[36] T. Wichtmann, H. A. Rondón, A. Niemunis, T. Triantafyllidis, and A. Lizcano, "Prediction of permanent deformations in pavements using a high-cycle accumulation model," Journal of Geotechnical and Geoenvironmental Engineering, vol. 136, no. 5, pp. 728-740, 2010.

[37] A. Niemunis, T. Wichtmann, and T. Triantafyllidis, "A highcycle accumulation model for sand," Computers and Geotechnics, vol. 32, no. 4, pp. 245-263, 2005.

[38] K. Johnson, "Plastic flow, residual stress and shakedown in rolling contact," in Contact Mechanics and Wear of Rail/Wheel Systems II, G. M. L. Gladwell, H. Ghonem, and J. Kalousek, Eds., pp. 83-97, 1987.

[39] T. Wichtmann, A. Niemunis, and T. Triantafyllidis, "Strain accumulation in sand due to cyclic loading: drained triaxial tests," Soil Dynamics and Earthquake Engineering, vol. 25, no. 12, pp. 967-979, 2005. 

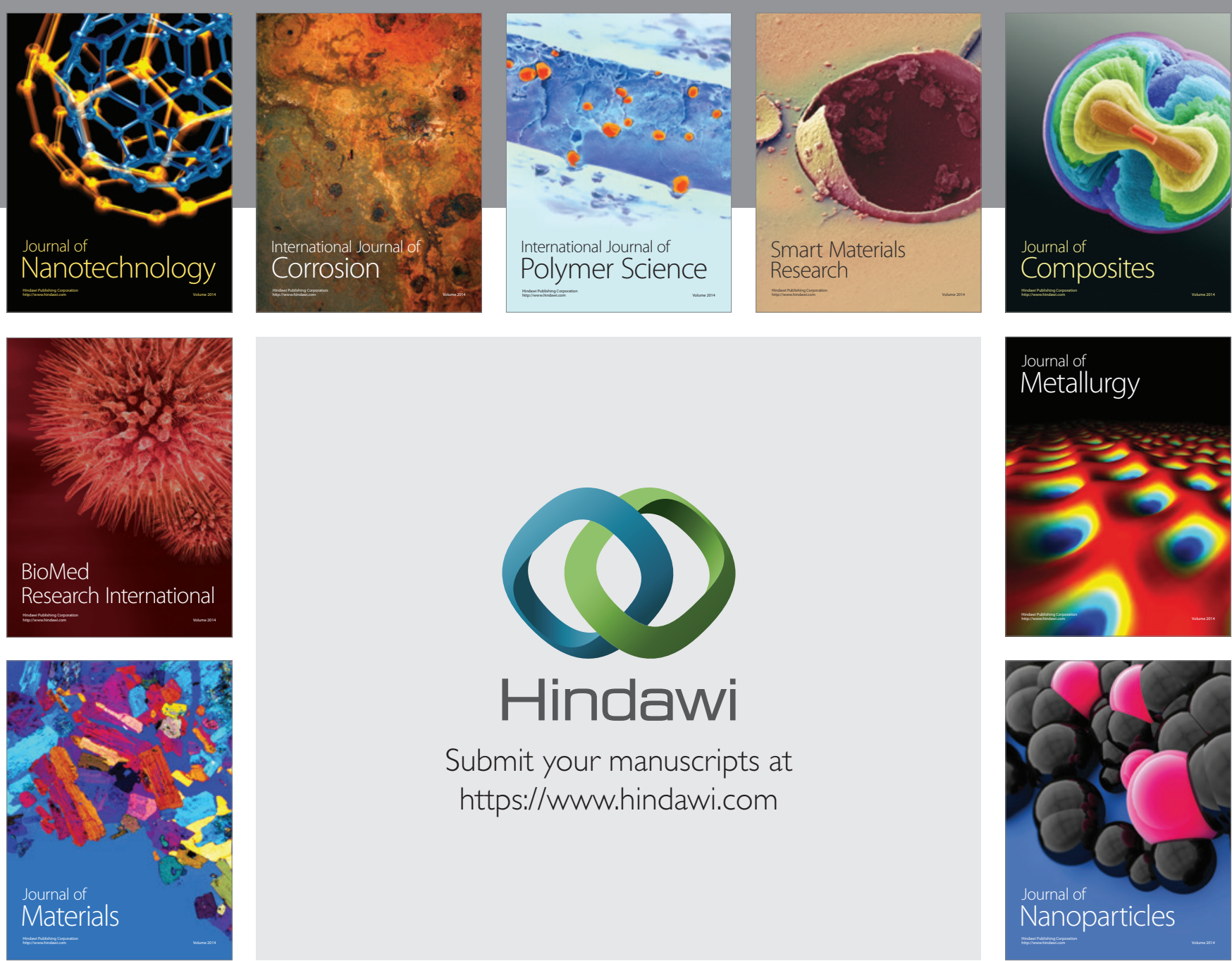

\section{Hindawi}

Submit your manuscripts at

https://www.hindawi.com

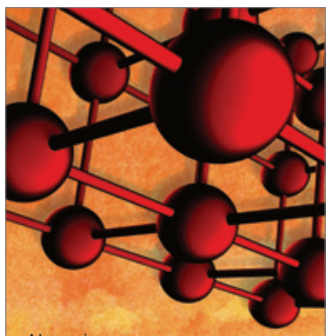

Materials Science and Engineering
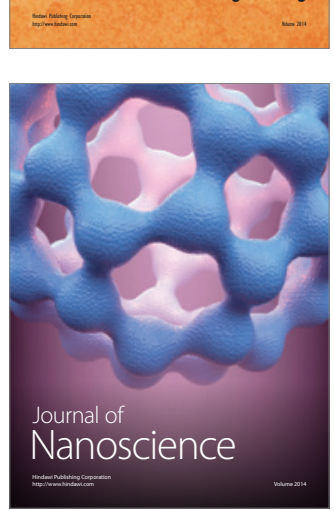
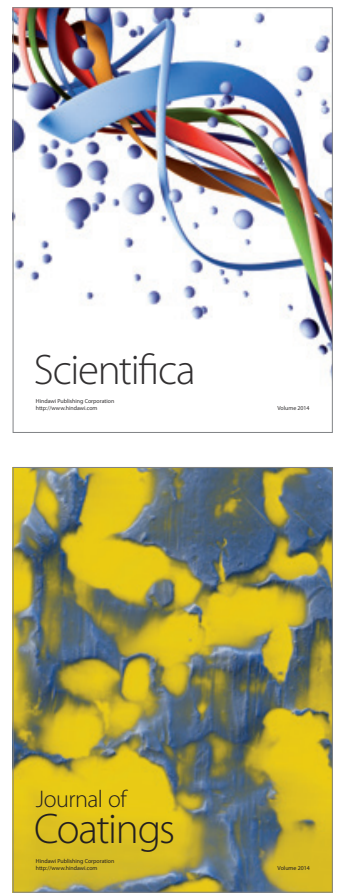
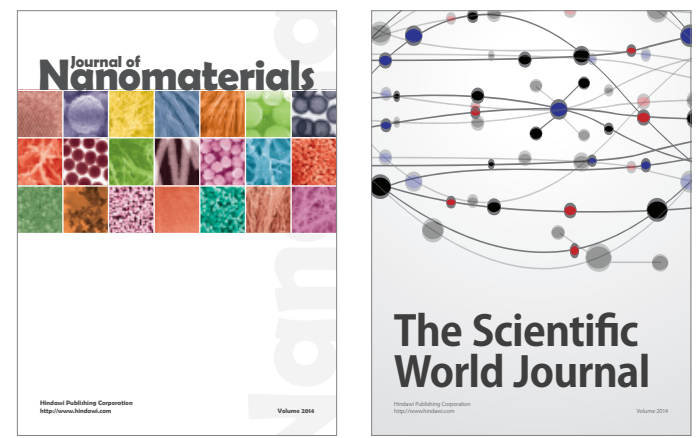

The Scientific World Journal

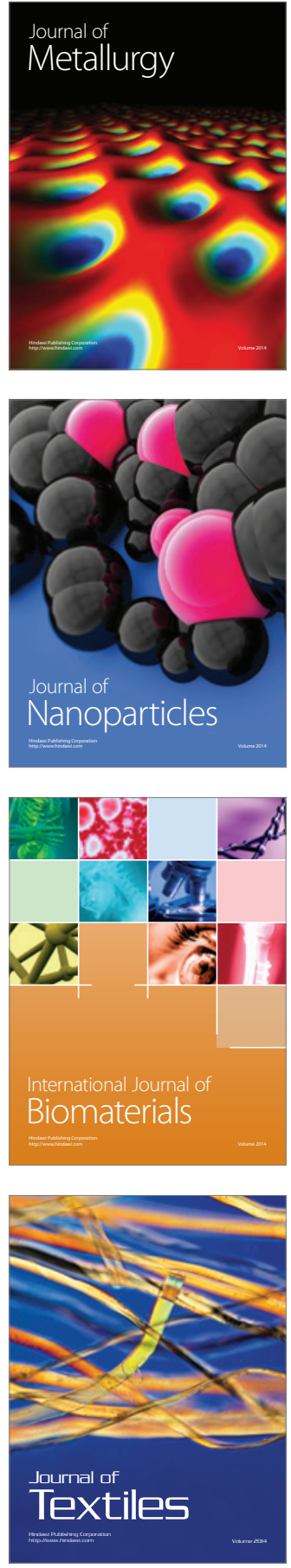